\title{
Shock-elicited aggression as a function of shock modality
}

\author{
STEPHEN F. DAVIS, JAMES L. TRAMILL, \\ JAMES W. VOORHEES, and MARY NELL MOLLENHOUR \\ Austin Peay State University, Clarksville, Tennessee 37040 \\ and \\ ROBERT E. PRYTULA \\ Middle Tennessee State University, Murfreesboro, Tennessee 97132
}

\begin{abstract}
Three groups of rats received ac, half-wave (pulsating) dc, and full-wave (filtered) dc shock, respectively, in a shock-elicited aggression situation. Results indicated that half-wave dc shock produced significantly more aggressive responses than did the other two shock modalities.
\end{abstract}

Subsequent to an article by O'Kelly and Steckle (1939) shock-induced fighting and/or aggression has received considerable research attention. Initially, these studies typically employed a pair of animals confined to a testing chamber. Aggression between the two animals, produced by an aversive stimulus (usually electric shock), was observed and reported. Numerous variables have been found to affect the amount of fighting shown in this situation. Among these are shock intensity, floor area, and pain modality (Ulrich \& Azrin, 1962), age and housing conditions (Creer \& Powell, 1971), and species employed (Dunstone, Cannon, Chickson, \& Burns, 1972; Ulrich, Wolff, \& Azrin, 1964).

Azrin, Rubin, and Hutchinson (1968), concerned with the reliance upon subjective evaluation of movements and postures that were considered to be aggressive, developed a method by which individual rats could be made to bite an inanimate target object. This procedure involved the application of unavoidable tail shocks to a restrained rat. Aggressive responses toward the target object located in front of the animal were automatically recorded, thus yielding a more objective measure of aggression. As with the paired-animal technique, a number of variables have been investigated. For example, severity of deprivation state (Cahoon, Crosby, Dunn, Herrin, Hill, \& McGinnis, 1971; Hamby \& Cahoon, 1971; Devine, Note 1) and lithium chloride dosage (Bisbee \& Cahoon, 1973) have been found to influence aggression in this situation.

Surprisingly, only a few studies investigating shock intensity and/or shock modality (i.e., type of shock) have been reported. Ulrich and Azrin (1962) reported

This research was sponsored, in part, by a Tower Fund research grant from Austin Peay State University to the first author and a faculty research grant from Middle Tennessee State University to the last author. that a shock intensity of $2.00 \mathrm{~mA}$ produced the greatest number of fighting responses. Higher and lower intensities resulted in fewer aggressive responses. Along similar lines, Azrin, Ulrich, Hutchinson, and Norman (1964) reported a direct relationship between shock duration and fighting. In a study manipulating both intensity and duration, Dreyer and Church (1968) reported that a $2.00-\mathrm{mA}$ shock produced more fighting between paired rats than did a 1.30 -mA shock. Further, increased durations resulted in increased fighting for both intensities. More recently, Follick and Knutson (1974) reported a study in which both shock modality (ac, ac rectified, and dc) and intensity (four levels) were manipulated. Their results indicated that dc footshock resulted in more fighting between paired rats at low shock intensity. At higher intensities, no differences were found.

This type of study, in which shock modality has been manipulated, appears to have been limited to the pairedanimal situation. The present study was designed to determine what, if any, relationship exists between shock modality and shock-elicited aggression when the single-animal, restrained technique is used.

\section{METHOD}

\section{Subjects}

Twenty-four male albino Holtzman rats approximately 150 days old served as subjects. All subjects were housed individually with food and water freely available.

\section{Apparatus}

An opaque tube $(21.5 \mathrm{~cm}$ in length, $7.5 \mathrm{~cm}$ in diam) mounted on a Plexiglas sheet served as the restraining device. The aggression target consisted of a Lafayette Instruments omnidirectional lever (Model 80111) mounted on a wooden platform. When the restraining tube was in place on the platform, the lever was parallel to, and $1.50 \mathrm{~cm}$ from, the open end of the tube. A $1.00-\mathrm{cm}$ movement of the lever was required to activate the attached microswitch. Closure of the microswitch, in turn, activated a pulse former which activated a Lafayette (Model 5707PS) impulse counter. 
A $1.50-\mathrm{cm}$ hole at the enclosed end of the tube allowed the subject's tail to be extended from the apparatus. Once in place in the apparatus, a wooden restraining rod was secured to the subject's tail by adhesive tape. Two pieces of No. 14 copper wire were permanently attached to the restraining rod, $7.00 \mathrm{~cm}$ apart, and served as electrodes. A Lafayette (Model 85204) shock source was modified to allow the presentation of (1) ac shock, (2) half-wave (pulsating) dc shock, or (3) full-wave (filtered) dc shock.

\section{Procedure}

Three equal groups $(n=8), A C$, DC-HW, and DC-FW, were randomly formed at the beginning of the experiment. Subjects in Group $\mathrm{AC}$ received ac shock during experimental testing, while those in Groups DC-HW and DC-FW received half-wave dc and full-wave dc shocks, respectively. A subject's experimental session was conducted as follows. First, the subject was placed in the restraint tube. Then electrode paste was applied to the electrodes and the restraining rod taped in place. Following a 5-min habituation period, each subject received a 10 -min period of shock administration. During this time $1.50-\mathrm{mA}$ shocks of $300-\mathrm{msec}$ duration were administered at 3 -sec intervals. Thus, each subject received a total of 200 shocks. The order for running subjects was randomized. The number of aggressive responses was recorded for each animal.

\section{RESULTS AND DISCUSSION}

Prior to analysis all data were converted to $\log _{10}$ $(\mathrm{X}+1)$ scores. Group mean scores appear in Figure 1 . Analysis of variance indicated that shock modality had a significant effect $[F(2,21)=6.80, p<.01]$. The Newman-Keuls procedure was employed to ascertain specific effects, and indicated that Groups AC and DC-FW did not differ from each other. However, Group DC-HW was found to be significantly $(p<.01)$ more aggressive than both Groups AC and DC-FW.

These results suggest, rather strongly, that type of shock may have a distinct influence upon the amount of aggression displayed toward the target. Of course, it

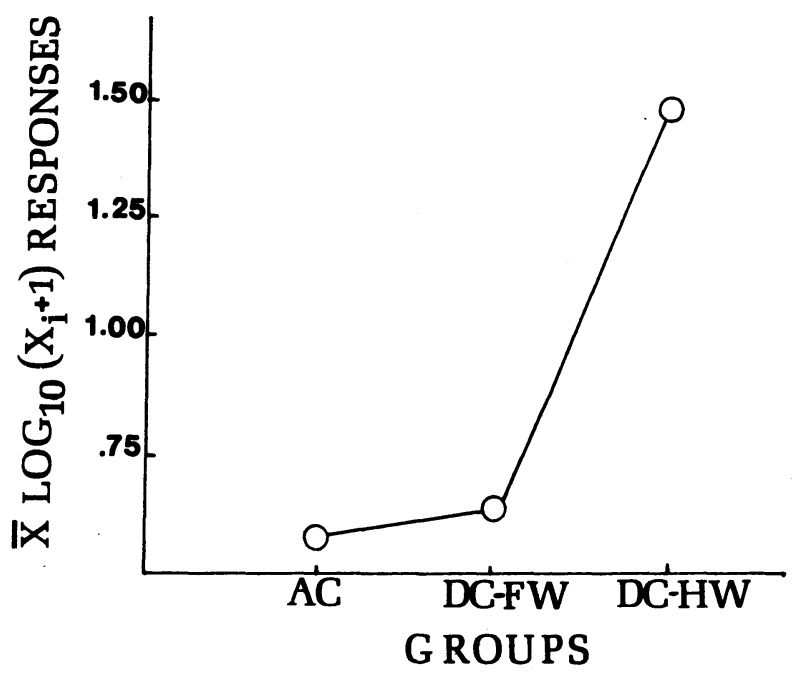

Figure 1. Group mean number of aggressive responses. is possible that these results are unique to the shock intensity and/or duration employed. Thus, further parametric studies appear to be needed in this area.

Several additional points also appear to merit consideration. First, albeit subjective, it was consistently observed that the subjects in Group AC displayed a two-stage pattern of responding. The initial component, lasting approximately $5 \mathrm{~min}$, consisted of vigorous attempts to direct aggression toward the point of shock administration (i.e., the tail). Subjects frequently attempted to turn around in the restraint tube rather than attack the target bar. The second stage consisted of the subject literally laying in the tube emitting vocalizations when shock was applied. Little aggression of any type was shown during this time. Upon removal from the tube, the subjects appeared to be much more debilitated than those in the other groups. This would certainly caution against the use of ac shock in studies employing repeated testing conditions.

Second, extreme care should be exercised in describing the type of shock used. For example, it is not atypical to see the designation "ac rectified" (or "ac rec.") in articles in this area. However, "ac rec." could be used to stand for either half-wave or full-wave (nonfiltered) dc shock. As noted above, shock modality may have an influence on the amount and/or type of aggression displayed.

\section{REFERENCE NOTE}

1. Devine, M. D. A parametric investigation into the effects of water deprivation on shock-elicited aggression. Unpublished master's thesis, Auburn University, 1971.

\section{REFERENCES}

Azrin, N. H., Rubin, H. B., \& Hutchinson, R. R. Biting attack by rats in response to aversive shock. Journal of the Experimental Analysis of Behavior, 1968, 11, 633-639.

Azrin, N. H., Ulrich, R. E., Hutchinson, R. R., \& Norman, D. G. Effect of shock duration on shock-induced fighting. Journal of the Experimental Analysis of Behavior, 1964, 7, 9-11.

Bisbee, D. S. P., \& Cahoon, D. D. The effects of induced nausea upon shock-elicited aggression. Bulletin of the Psychonomic Society, 1973, 1, 19-21.

Cahoon, D. D., Crosby, R. M., Dunn, S., Herrin, M. S., Hill, C. C., \& McGinnis, M. The effect of food deprivation on shock-elicited aggression. Psychonomic Science, 1971, 22, 43-44.

Creer, T. L., \& Powell, D. A. Effects of age and housing conditions on shock-induced aggression. Psychonomic Science, 1971, 22, 259-261.

Dreyer, P. I., \& Church, R. Shock-induced fighting as a function of the intensity and duration of the aversive stimulus. Psychonomic Science, 1968, 10, 271-272.

Dunstone, J. J., Cannon, J. T., Chickson, J. T., \& Burns, W. K. Persistence and vigor of shock-induced aggression in gerbils. Psychonomic Science, 1972, 28, 272-274.

Follick, M. J., \& KNUTson, J. F. Shock source and intensity: Variables in shock-induced fighting. Behavior Research Methods \& Instrumentation, 1974, 6, 477-480. 
Hamby, W. G., \& Cahoon, D. D. The effect of water deprivation upon shock elicited aggression in the white rat. Psychonomic Science, 1971, 25, 166-167.

O'Kelly, L. I., \& Steckle, L. C. A note on long enduring emotional responses in the rat. Journal of Psychology, 1939, $8,125-131$.

Ulrich, R. E., \& Azrin, N. H. Reflexive fighting in response to aversive stimulation. Journal of the Experimental Analysis of Behavior, 1962, 5, 511-520.

Ulrich, R. E., Wolff, P. C., \& AzRin, N. H. Shock as an elicitor of intra- and inter-species fighting behavior. Animal Behavior, 1964, 12, 14-15.

(Received for publication September 24, 1976.) 